\title{
Worth Waiting For: Increasing Satisfaction by Making Consumers Wait
}

\author{
Michael D. Giebelhausen, Cornell University \\ Stacey G. Robinson, Florida State University \\ J. Joseph Cronin Jr., Florida State University
}

\begin{abstract}
A truism in the marketing literature, and among many marketing practitioners, is that requiring consumers to wait negatively impacts quality evaluations, purchase intentions and a range of other important outcomes. However, it is also true that consumer waiting or queuing has historically been considered from an operations perspective. The present research takes a different approach and examines waits in the context of their ability to function as a signal of quality. Four experiments demonstrate a required wait can indeed signal quality to consumers and increase, rather than decrease, both purchase intentions and actual experienced satisfaction. Three moderators of this effect are examined: preexisting knowledge, consumption motivations, and the extent to which quality is difficult to objectively determine. The results suggest in situations where quality is important, unknown or ambiguous, managers may increase consumer satisfaction by making consumers wait.
\end{abstract}

The academic literature describes waiting as a phenomenon that solicits anger, tension, frustration, and a variety of other negative emotions and cognitions (Brady and Cronin 2001; Dabholkar and Bagozzi 2002; Dube-Rioux et al. 1989; Hui and Tse 1996; Taylor 1994). The relationship between waiting and evaluations has been called "intuitively straightforward" in that the longer consumers wait, the lower their subsequent evaluations will be (Taylor 1995, p. 39). In general, waiting research has focused on the negative relationship between waiting and consumer evaluations (Antonides et al. 2002). As such, waiting is said to adversely affect overall product evaluations, and firms are counseled to eliminate waits (Baker and Cameron 1996; Taylor 1994). Companies, perhaps motivated by this message, spend billions of dollars annually attempting to reduce the time consumers wait (Koeppen 2007).

However, it is not difficult to find circumstances in which consumers seem willing to wait. Consumers frequently wait to acquire and consume a number of products and services (Kumar et al. 1997); they wait to be seated in restaurants, for salon appointments, for tickets to events, for the latest 
cell phones and so on. In fact, consumers spend two to three years of their life waiting (Cox 2005). Again, while the marketing literature provides much commentary on the phenomenon of waiting, the single-minded assumption is waiting negatively affects consumer perceptions of quality, thereby negatively impacting service evaluations, purchase intentions and satisfaction (Berry et al. 2002; Hui and Tse 1996). Yet, if waiting is such a universally negative phenomenon, one would expect consumers to wait far less than they actually do (Becker 1991).

In reality, consumers often seem attracted by the presence of a wait, and some marketers appear to actively promote the idea waiting is required. Most of us have observed a long line outside of a less than full nightclub or have waited for a table at a restaurant where an undersized reception area forces patrons to spill out onto the sidewalk. Some retailers have gone so far as to pay actors to create lines in front of their stores to generate interest from genuine consumers (Borowski 2008). It appears as though some practitioners may perceive potential positive results from requiring consumers to wait. The fact this apparent lay-theory has yet to be empirically examined within the academic marketing literature represents an omission this research hopes to address. The results have important implications for marketing practitioners, many of whom spend large sums of money attempting to eliminate waits.

While people may dislike waiting in general, it is unmistakably a common daily occurrence. Given its pervasiveness in everyday life, the effects associated with consumer waiting should be a comprehensively researched area, yet the current research is limited and much of it conducted by operations researchers not focused on the psychological aspects of waiting; rather waits are viewed as operational failures in need of fixing (Carmon et al. 1995; Durrande-Moreau and Usunier 1999). This research takes a paradoxical view of waiting. That is, in some circumstances, a wait does not create negative perceptions, but rather increases perceived quality, purchase intentions and ultimately satisfaction. This expanded conceptualization of waiting is needed given the phenomenon's current unidimensional consideration within the literature and strategic importance.

The intended contribution of the present research is simply to: (1) empirically demonstrate, contrary to the extant literature, waits can have a positive impact on consumer purchase intentions and satisfaction, (2) illustrate a potential mechanism through which this effect operates, and (3) suggest several variables moderating this relationship. Study 1 demonstrates a positive relationship between the presence of a wait and perceived quality and shows how the relationship can be attenuated by preexisting attitudes. Study 2 reveals how, across a variety of different services, quality perceptions function as the mechanism by which a required wait can increase purchase intentions. Study 3 shows 
how the presence of a wait can actually increase one's experienced satisfaction. Lastly, Study 4 demonstrates how the act of waiting can increase perceived quality, purchase intentions and experienced satisfaction when the product is difficult to evaluate objectively. These findings suggest that, in many cases, eliminating waits may actually decrease consumer satisfaction and that both managers and academics should adopt a more multi-dimensional perspective of wait times.

\section{Conceptual Background}

Consumers are often in situations in which quality is difficult to determine. For example, a product or service provider may simply be new to the market. Alternatively, it might be the consumer who is new to, or unfamiliar with, the market. In general, services are difficult to evaluate due to their inherent characteristics (Murray 1991). Even in the case of physical goods, instances in which quality is unobservable are commonplace (Boulding and Kirmani 1993). Because quality is often ambiguous, consumers regularly rely on signals, or cues, when forming opinions of a good or service (Boulding and Kirmani 1993; Kirmani and Rao 2000). Consumer evaluations can be determined primarily by signals in situations where quality is presumed to be ambiguous. For example, Ariely (2008) demonstrated coffee taste evaluations were significantly impacted by whether condiments were presented in expensive silver containers or torn Styrofoam cups. The following presents theoretical justification for how the presence of a wait functions as an important signal of quality.

\section{Waiting as a Cost}

Various signals of quality such as price, physical features, provider reputation, and branding inform consumers (Dawar and Parker 1994). The literature refers to price as a commonly used signal (cf., Dawar and Parker 1994; Kirmani and Rao 2000). Price is well established in the marketing literature as an extrinsic cue theorized to serve as a quality indicator (Rao and Monroe 1989), even to the extent that price is called a "surrogate for quality" in the absence of other information (Zeithaml 1988, p. 8).

The effect of price on services decision making is not limited to monetary considerations as price is not the only cost associated with obtaining a service. A non-monetary price component is also associated with service acquisition (Bitner 1990; Zeithaml 1988). Specifically, time spent waiting for services "has an economic value to the consumer" and time and effort costs incurred in the process of buying are referred to as a "time price" (Baker et al. 2002, p. 122). It is suggested the longer consumers wait, or experience a loss of time, the greater their perceived investment in a product (Leclerc et al. 1995). Thus, the literature provides support for the notion that just as price conveys quality, waiting 
time, as a proxy for price, conveys quality. Additionally, just as consumers avoid purchasing if a price is too high, when a price is perceived as too low, suspicions of quality arise (Dodds et al. 1991). Contradictory to existing theory on waiting, this suggests if there is "no wait," inferences of low quality may follow.

\section{Social Influence}

Waiting may also function as a form of social influence. It is well established that the actions of others are critical to consumer choice and consumption processes (Bearden and Etzel 1982). Playing a key role in the process of consumer choice, social influence is characterized as being normative and/or informational in nature (Bearden and Etzel 1982). When consumers conform to the expectations of others, normative social influence is in play. Informational social influence differs from the former in that it is based upon the need to make informed decisions, as is the case when faced with choice uncertainty. As such, consumers routinely seek credible information and are often influenced by others' evaluations as the perceptions and subsequent judgments of others are thought to be indicative of reality (Bearden and Etzel 1982; Burnkrant and Cousineau 1975; Deutsch and Gerard 1955).

While the vast majority of social influence research is focused on interactive forms of influence (Argo et al. 2005), social influence is not limited to interactive situations, but may be classified as noninteractive (Argo et al. 2005; Banerjee 1992; Dahl et al. 2001). Individuals are known to be influenced by the non-verbal actions of other consumers. Both real and implied actions of others affect subjective feeling and emotion (Ferraro et al. 2009; Latane 1981). Social Impact Theory emphasizes that consumers are affected by "the real, implied, or imagined presence or actions of other individuals" (Latane 1981, p. 343). Thus, simply observing others waiting may influence one's behavior. Likewise, evaluations regarding product quality or popularity based upon verbalized wait times may serve as an example of the inferred behavior of others. Interestingly, reliance on informational influence is magnified by decision uncertainty (Cialdini 2001). Therefore, as quality is difficult to assess or ambiguous, this form of influence becomes increasingly important.

In addition, just as word of mouth (WOM) influences consumer decision making by affecting perceptions and attitudes (Goldenberg et al. 2001; Grewal et al. 2003), nonverbal information exchanges, such as the behavior of other consumers, serves as a form of communication, perhaps an even more reputable form than traditional WOM. Behavior "carries greater social and scientific currency" than words (Nock 2008, p. 161). It is an accurate measure of a person's thoughts and feelings (Nock 2008). Consumers look to the behavior of others for guidance and use imitation as a practical 
heuristic given that behavior is thought to be a trustworthy form of information (Bonabeau 2004; Senecal and Nantel 2004).

To summarize, consumers looking to attenuate pre-purchase uncertainty may seek information from other consumers; once more, such information is considered to be reliable and evaluative (Murray 1991; Senecal and Nantel 2004). Both economics herd behavior and informational cascades theory, which state consumers pay attention and act in accordance with other consumers due to insight others may possess which they may be lacking, are consistent with the abovementioned research (Anderson and Holt 1997; Banerjee 1992). Similarly, consumer demand is thought to be dependent upon the demands of "other" consumers (Becker 1991). Clearly, waiting easily relays the actual or inferred behavior of other consumers and serves as a non-verbal form of communication that not only informs but also has the potential to influence behavior.

\section{Signal Diagnosticity}

The aforementioned depicts waiting as a cost consumers incur in a very public way, thereby having the ability to significantly impact other consumers. However, as with most effects in the social sciences, there are likely to be situations where it does not affect consumer behavior. Signals are used as cues for a variety of reasons when other information, such as pre-existing knowledge, is absent. Consumers rely more on external sources of information (e.g., observable cues, word of mouth) when there is a lack of product familiarity versus situations of known quality or certainty; they acquire information in an effort to reduce risk. The notion that most consumers make purchase decisions with some degree of uncertainty and seek information to attenuate risk is well established (cf., Murray 1991; Zeithaml 1988). Therefore, observable cues, such as waiting, are likely to be more influential in unknown product assessments.

Waiting is clearly an observable cue. It can be based on visual observation, or consumers can be informed they must wait for service (e.g., a 2 week wait for an appointment). Service purchase decisions are especially difficult to evaluate due to their inherent experiential nature (Murray 1991). Therefore, when making decisions as to which services to purchase, consumers are likely to rely more heavily on cues. These cues, based upon available information (e.g., a visible line, a verbalized wait), allow consumers to make judgments about the unknown and provide a mechanism for quality expectations and evaluations (Baker et al. 2002; Blair and Innis 1996).

The literature notes consumer motivation may affect how waits are perceived. Delays are thought to be viewed more negatively if a consumer has an immediate need (Dube- Rioux et al. 1989). 
Additionally, individual consumers may be time sensitive and/or quality sensitive. Quality-sensitive buyers attempt to avoid the consequences associated with poor quality purchases (Kirmani and Rao 2000). Temporal-oriented consumers are impacted by time-related sensitivity (Berry et al. 2002). Decisions made by consumers constrained by time are likely to be more impacted by convenience compared with the decisions of consumers who are sensitive to quality, who are more likely driven by product excellence (Morganosky 1986). Therefore, it is reasonable to expect behavioral intentions to vary based upon consumer motivation. Nevertheless, the literature consistently portrays waiting as having a universally negative effect on consumers' quality evaluations, purchase intentions and overall satisfaction.

\section{Quality Perceptions, Purchase Intentions, and Satisfaction}

Up to this point, this conceptual review has focused primarily on how the presence of a wait functions as a signal of quality. It is arguably more important to practitioners, and perhaps researchers, to demonstrate how this signal translates into a measurable outcome such as purchase decision or satisfaction. There is a well-established positive relationship between perceived quality and purchase intentions (Baker et al. 2002; Cronin and Taylor 1992; Sirohi et al. 1998; Zeithaml et al. 1996). Thus, all else being equal, we expect a relationship between waiting and purchase intentions will be mediated by perceived quality. Of course, all else is rarely equal. For example, price sensitive consumers may be willing to give up quality in order to pay a lower price. Similarly, as waiting is conceptualized as a cost, time sensitive consumers may be unwilling to wait for a service with a line even if they perceive that line to be indicative of quality. The nature of this mediating process will likely be influenced, for example, by the extent to which individuals value quality over convenience. Therefore, the following hypotheses evaluate how waiting informs consumers and affects behavior given varying situations of product familiarity and consumer motivation:

H1: There is an interaction between familiarity and the presence of a wait such that, for an unfamiliar service, the presence of a wait increases perceived quality. However, for a familiar service the presence of a wait has no effect on perceived quality.

H2a: There is an interaction between consumer motivation and the presence of a wait such that, when the consumer's primary motivation is quality, the presence of a wait increases purchase intention. However, when the consumer is motivated by convenience the presence of a wait decreases purchase intentions. 
H2b: Perceived quality functions as a mechanism by which the presence of a wait influences purchase intentions.

As for the dependent variable of satisfaction, insight can be provided by the expectancy disconfirmation paradigm regarding satisfaction judgments (Oliver 1980). This paradigm suggests satisfaction is determined when expectations regarding product performance are compared against actual product performance evaluations. At the start of this conceptual review we pointed out situations in which objective quality is difficult to determine. The expectancy disconfirmation paradigm suggests when performance is difficult to objectively evaluate, satisfaction will be determined primarily from consumer expectations (Oliver 1980). Alternately stated, "the mind gets what it expects" (Ariely 2008, p. 155). Thus, it is reasonable to hypothesize that waiting may increase experienced satisfaction when quality is ambiguous. In addition, it is also reasonable to hypothesize that perceived quality will mediate the relationship between waiting and experienced satisfaction.

H3a: When product quality is ambiguous, there is a positive main effect of a wait such that experienced satisfaction will be greater when a wait is present than when a wait is absent.

H3b: When product quality is ambiguous, perceived quality functions as a mechanism by which the presence of a wait increases experienced satisfaction.

\section{Study 1}

The primary goal of Study 1 was to empirically demonstrate waiting could indeed result in a positive outcome. In particular, this study tested the assertion that the presence of a wait can result in heightened perceptions of quality. Additionally, Study 1 examined the extent to which the presence of preexisting attitudes moderates this relationship. The literature on signaling and heuristic information processing suggests signals are less influential when an individual already maintains a well-defined attitude toward an object (Chaiken and Stangor 1987). Thus, when there is a preexisting attitude regarding product quality, the ability of a wait to increase perceived quality should be attenuated.

\section{Study 1 Design}

Study 1 utilized, a 2 (wait: absent, present) x 2 (familiarity: unknown service, well-known service) between-subjects experimental design. One hundred twenty-seven (127) participants, recruited from an introductory marketing class, completed the study in an online behavioral lab setting. Course credit served as incentive for participation. In order to avoid relying solely on student responses, 108 
nonstudent subjects were recruited by students enrolled in an upper-level marketing class. The student recruiters were unaware of the nature of the study and received course credit for enlisting a nonstudent subject (e.g., family member, manager, etc.); responses were randomly spot checked to ensure compliance. The ages of the non-student sample ranged from 30 to 63 with a mean age of 46.8 and were $58 \%$ female. The two resulting datasets were combined in order to provide a more diverse sample. It should be noted that no differences in response patterns were found between the two groups.

\section{Study 1 Stimulus and Procedure}

Participants read a randomly selected consumption scenario featuring a character named Pat. The name Pat was selected based on the scenario research convention of using gender ambiguous names that allow both males and females to identify with the scenario protagonist (Bendapudi and Leone 2003). Participants were instructed to imagine themselves as Pat when responding to the study items.

In the "well-known service" condition, a pretest identified a service that, for both the student and non-student samples, was very familiar, exhibited stable perceptions of quality, and was reasonably well liked. The service selected was that of a highly advertised, national casual-dining chain. For the "unknown service" condition, a corresponding fictional restaurant brand was created to insure participants would have no knowledge of the restaurant. In the "wait absent" condition, the scenario indicated the waiting area was empty and Pat can be seated right away. In the "wait present" condition, the waiting room was full and Pat must wait 45 min to be seated (see Appendix A for full scenario text).

\section{Study 1 Results and Analysis}

In order to ensure participants perceived a difference between being seated immediately and a 45 min wait, two items were adapted from Cronin et al. (2000) measure of service sacrifice: "The time required to use this facility is" and "The effort required to use this facility is" (very low, very high). ANOVA indicated a significant main effect of this manipulation $\left(M_{\text {wait_absent }}=4.58, M_{\text {wait_present }}=6.30, F(1\right.$, 233) $=54.88, p<.001$ ) on the combined student and non-student data.

Taylor and Bearden's (2002) four item measure of perceived quality was used to evaluate the present dependant variable of interest (see Appendix B for all measures and Table 3 for convergent and discriminant validity analysis). Participant type (student/non-student) was included as a third factor in the ANOVA for Study 1. The purpose of this was to evaluate whether there was a significant difference in the hypothesized interaction ( $\mathrm{H} 1$ ) between the two participant types. The three-way interaction was 
insignificant $(F(1,227)=1.77, p=.185)$ suggesting the responses of the students did not differ substantially from those of the non-student sample.

Consistent with $\mathrm{H} 1$, this analysis demonstrated a significant interaction between wait and familiarity $(F(1,227)=14.345, p<.001)$. The simple effects contrasts indicated the presence of a wait significantly increased perceived quality for the unknown service provider $\left(M_{\text {wait_absent }}=5.93, M_{\text {wait_present }}=\right.$ $6.99, F(1,227)=19.426, p<.001)$. Also, as predicted by $H 1$, the effect of a wait on perceptions of quality regarding the known service provider was insignificant $\left(M_{\text {wait_absent }}=6.77, M_{\text {wait_present }}=6.54, F(1\right.$, 227)=.937, $p=.334$ ) (Fig. 1).

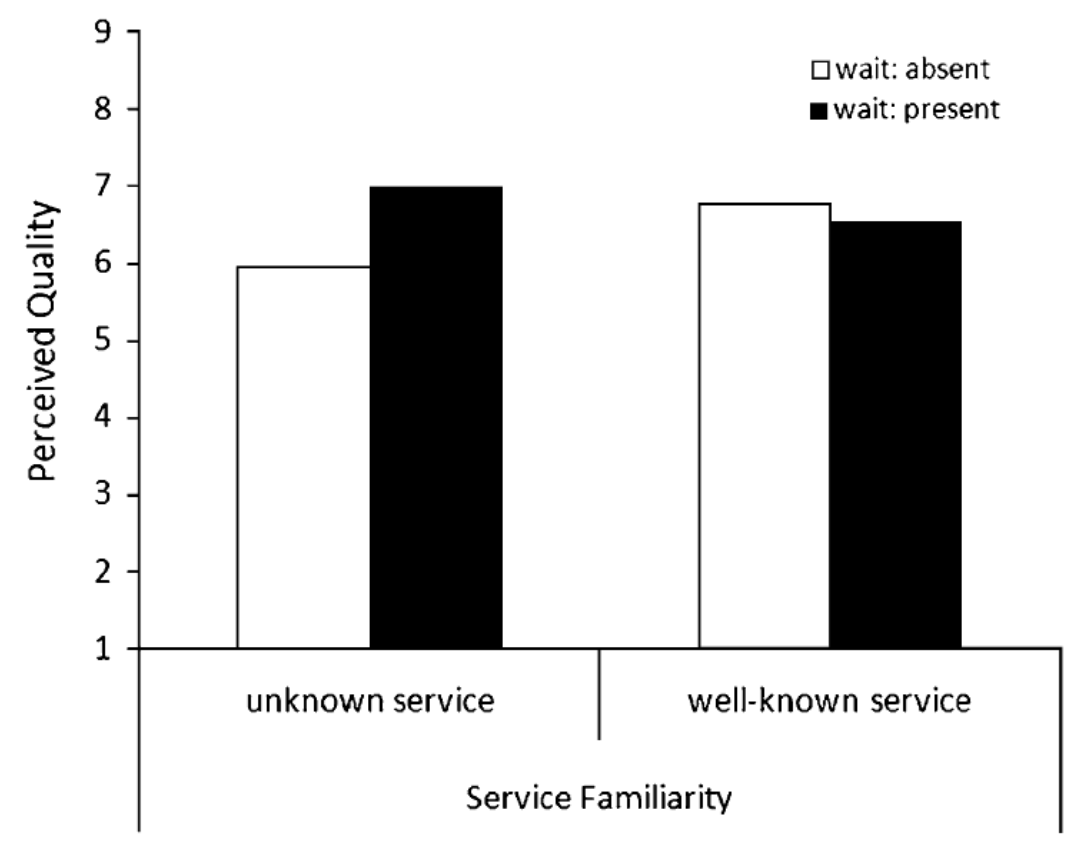

Fig. 1 Study 1 -Perceived quality

\section{Study 1 Discussion}

The goal of Study 1 was two-fold. The main objective was to empirically demonstrate, contrary to the extant marketing literature, it is possible for waiting to have a positive outcome. In this case, the positive outcome was increased quality perceptions. The second objective of Study 1 was to demonstrate one potential moderator of this effect: the extent to which the consumer already maintained an attitude about the product. Response patterns were consistent with the hypothesized effects and demonstrated no significant difference between the student and non-student samples. In summary, while the presence of a wait in the scenario increased perceived quality for the fictitious 
restaurant brand, the presence of a wait had no effect on quality perceptions regarding the well-known national brand.

A limitation of this study is it only considers one particular service setting. Examining a variety of other services would greatly contribute to the generalizability of the findings. Similarly, Study 1 only examines one manifestation of what constitutes a "wait," namely sitting in a restaurant waiting area. Replicating this phenomenon across other manifestations of service delays would also enhance the generalizability and importance of the findings. It would also be useful to examine outcome variables downstream from perceived quality (e.g., purchase intentions). Lastly, in addition to service familiarity, there are undoubtedly a number of other moderators that could influence the effect of a wait.

\section{Study 2}

Study 2 extends Study 1 by examining: (1) the dependent variable of purchase intentions, (2) quality as a mediator, (3) a wider variety of service settings, (4) different manifestations of wait, and (5) consumer motivations as a moderating variable. Specifically, Study 2 examines how the presence or absence of a wait affects purchase intentions for consumers motivated by either convenience or quality across service settings ranging from an auto mechanic to a physician. The extent to which perceived quality mediates the relationship between a wait and purchase intentions was also examined.

\section{Study 2 Design}

This study utilized a 2 (wait: absent, present) x 2 (consumer motivation: convenience, quality) within-subjects experimental design. This design was executed with a sample of 122 undergraduate students, recruited from a basic marketing course, who participated in exchange for course extra-credit. Additionally, the non-student sample recruited in Study 1 completed this study in order to bolster the external validity of the findings.

\section{Study 2 Stimulus and Procedure}

After logging into the study via an online laboratory, participants read a series of six short scenarios. Four of the scenarios were relevant to the experimental conditions and two served as distracters. To minimize the number of experimental condition scenarios viewed concurrently, the distracter scenarios appeared at position 1 and 3 in the series (see Appendix A). Again, the character in the scenarios was named Pat. However, to allow for additional flexibility in crafting the scenario text, the pronouns appearing in the scenarios were dynamically adjusted based on the gender of the 
participant as indicated by their response to a question on the first screen of the study (see Appendix A for scenario text).

As mentioned above, to enhance the generalizability of the findings, highly disparate services including an auto mechanic, restaurant, medical doctor, and night club were selected. The scenarios were designed to reinforce perceptions that Pat was unfamiliar with the featured service provider. The "wait" conditions were manipulated in two ways. For the nightclub and restaurant, wait was manipulated via the presence or absence of a physical line. For the mechanic and medical doctor, wait was manipulated by the number of days before the next available appointment.

For each of the four service settings, four different scenarios were created, one representing each of the conditions implied by the 2 (wait: absent, present) x 2 (motivation: quality, convenience) design, resulting in sixteen total scenarios. A computer program was written to randomly assign each participant a set of four scenarios from the sixteen options. The program ensured each experimental condition and each service setting was represented within a participant's set. Via this methodology, each participant had an equal chance of being assigned to one of 576 possible combinations of randomly ordered service settings and experimental conditions.

\section{Study 2 Results and Analysis}

Oliver and Swan's (1989) measure of purchase intentions was used to evaluate the outcome variable of interest. A within-subjects ANOVA was conducted on the combined student and non-student data. As with Study 1, participant type (student/non-student) was included as an additional factor, and was found to have a statistically insignificant impact on the response patterns $(F(1,227)=1.59, p=.209)$. More pertinent to the hypotheses, the analysis revealed a significant interaction between motivation and wait in determining purchase intentions $(F(1,227)=36.17, p<.001)$. Simple main effect contrasts indicated, in scenarios where convenience was the primary motivator, the presence of a wait resulted in significantly lower purchase intentions ( $\left.M_{\text {wait_absent }}=6.01 M_{\text {wait_present }}=4.88, F(1,227)=26.69, p<.001\right)$. In scenarios where individuals were motivated by quality, however, the presence of a wait significantly increased purchase intentions $\left(M_{\text {wait_absent }}=5.35, M_{\text {wait_present }}=5.99, F(1,227)=9.57, p=.002\right)$. Consistent with Study 1, a within-subjects contrast revealed a positive main effect regarding the presence of a wait on perceived quality $\left(M_{\text {wait_absent }}=4.81, M_{\text {wait_present }}=6.73, F(1,229)=297.35, p<.001\right)$ (Fig. 2). 


\section{Study 2 Alternative Analysis}

Although this study utilized a within-subjects design, it is also possible to analyze it as if it were a between-subjects design in order to explore any differences between various contexts (i.e., scenarios). The benefit of this approach is that, rather than considering a range of consumption activities collectively across a participant, the merits of the individual scenarios can be evaluated. Reorganization of the dataset resulted in 918 usable observations (there were two instances of missing data) distributed across the four scenarios. An ANOVA, with scenario context included as a third factor, demonstrated a significant three way interaction $(F(3,902)=4.56, p=.003)$. This indicated that the interaction of motivation and wait in determining purchase intentions was not equivalent across the scenarios. In order to explore this three-way interaction further, separate analyses were conducted on the subsets of the data relating to each scenario. While the mechanic, restaurant, and night club scenarios generated a significant interaction between wait and motivation ( $p<.001, p=.003$, and $p<.001$ respectively), the medical doctor scenario did not $(p=.928)$. Rather, there was a significant decrease in purchase intentions when participants were told that they have to wait 2 months in order to receive a vaccination required for an upcoming trip abroad. Perhaps it was simply that participants did not notice the trip was 3 months away, thereby giving them a month to spare, or maybe waiting 2 months for a routine shot is simply too long. Alternatively, perhaps getting a vaccination is not a service where participants perceive there to be a large disparity in terms of quality and thus, convenience won.

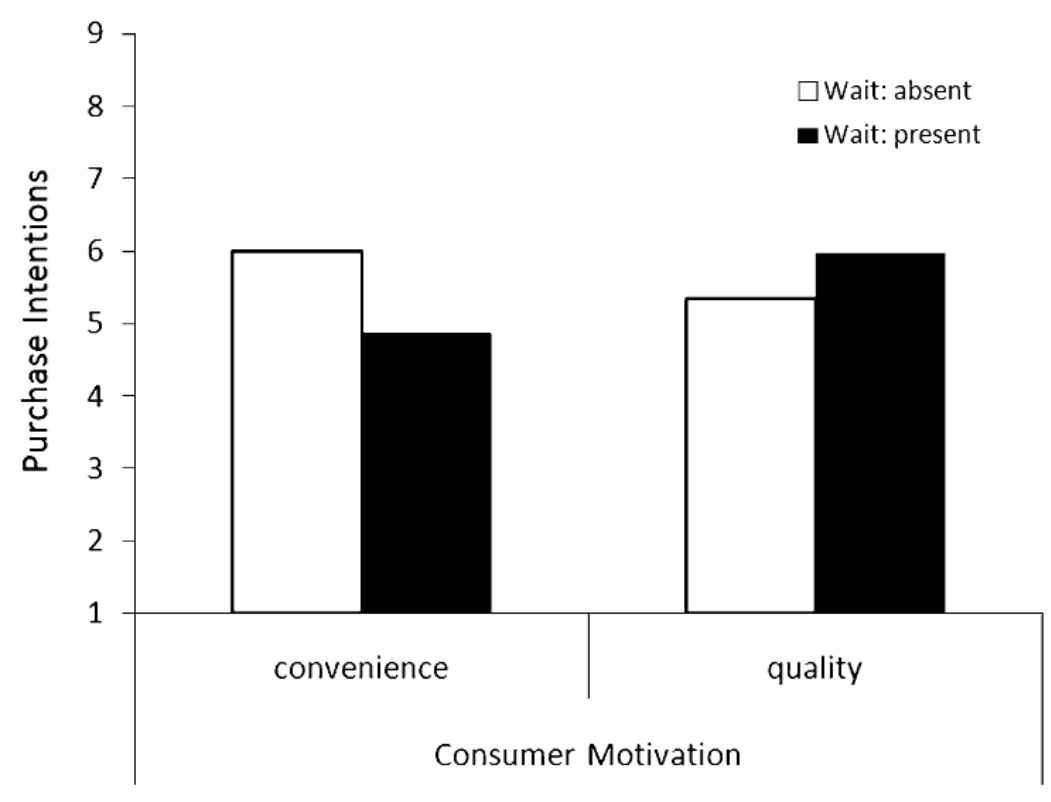

Fig. 2 Study $2-$ Purchase intentions (within subjects) 
Table 1 Study 2 -Alternative analysis contrasts

\begin{tabular}{|c|c|c|c|c|c|c|c|c|c|c|}
\hline \multirow[b]{2}{*}{ Scenario } & \multicolumn{5}{|c|}{ Quality motivated } & \multicolumn{5}{|c|}{ Convenience motivated } \\
\hline & No wait & Wait & Mean diff & $\mathrm{F}$ & Sig. & No wait & Wait & Mean diff & $\mathrm{F}$ & Sig. \\
\hline Mechanic & 5.00 & 5.64 & 0.65 & 3.34 & 0.035 & 6.39 & 4.22 & -2.17 & 35.05 & $<.001$ \\
\hline Restaurant & 5.61 & 6.65 & 1.04 & 8.73 & 0.002 & 6.07 & 5.57 & -0.50 & 1.80 & 0.091 \\
\hline Night club & 5.10 & 6.70 & 1.60 & 12.50 & $<.001$ & 6.05 & 5.15 & -0.90 & 4.28 & 0.020 \\
\hline
\end{tabular}

Across the three scenarios where there was a significant interaction, five of the six simple effect contrasts were consistent with the within-subjects analysis. There was a significant increase in purchase intentions when individuals motivated by quality were told they would have to wait and a significant decrease in purchase intentions when individuals motivated by convenience were told they would have to wait (see Table 1). The exception was the Sunday morning brunch scenario. For this scenario, the decrease in purchase intentions in the convenience motivation condition was insignificant $\left(M_{\text {difference }}=-.503, p=.091\right)$.

\section{Mediation Analysis}

A mediation analysis, following the four step procedure outlined by Baron and Kenny (1986), was conducted to determine whether quality perceptions mediated purchase intentions. With regards to the initial effect of wait presence, for participants in the quality motivated condition, there was both a positive and significant relationship between a required wait and purchase intentions (see Table 2). Conversely, for participants in the convenience condition, this relationship was negative and significant. For both groups, there was a positive and significant relationship between a wait and perceived quality. Additionally, for both groups, there was a positive and significant relationship between perceived quality and purchase intentions.

For quality motivated individuals, in step four (where both perceived quality and wait are included as predictors) the relationship between a required wait and purchase intentions switched from being positive and significant to being negative and significant. Alternatively stated, after controlling for the positive effect of a wait on perceived quality, the remaining relationship between a wait and purchase intentions was revealed to be negative. For these quality motivated individuals, the positive effect of a wait (operating via perceived quality) was simply strong enough to obscure the otherwise negative effect of a wait. This pattern indicates an instance of competitive mediation, as described by Zhao et al. (2010), whereby a mediated effect and direct effect co-exist but have opposite signs. 
Table 2 Study 2-Mediation analysis results

\begin{tabular}{lllll}
\hline & Step 1 & Step 2 & Step 3 & Step 4 \\
\hline $\begin{array}{l}\text { Quality motivated } \\
\text { a Wait to purchase intentions }\end{array}$ & $\mathrm{B}=.127, p=.008$ & & & $\beta=-.225, p<.001$ \\
$\begin{array}{l}\text { Wait to perceived quality } \\
\text { Perceived quality to purchase intentions }\end{array}$ & & $\beta=.514, p<.001$ & & $\beta=.684, p<.001$ \\
$\begin{array}{l}\text { Convenience motivated } \\
\text { bWait to purchase intentions }\end{array}$ & $\mathrm{B}=-.312, p<.001$ & $\beta=.568, p<.001$ & $\beta=-.583, p<.001$ \\
$\begin{array}{l}\text { Wait to perceived quality } \\
\text { Perceived quality to purchase intentions }\end{array}$ & & $\beta=.402, p<.001$ & & $\beta=.672, p<.001$ \\
\hline
\end{tabular}

${ }^{\mathrm{a}}$ After controlling for perceived quality, this relationship switches from positive and significant to negative and significant

${ }^{\mathrm{b}}$ After controlling for perceived quality, the relationship between wait and purchase intention becomes more negative

The finding of Baron and Kenny's procedure ending in a significant relationship between the initial variable and outcome variable, albeit in the opposite direction, may seem strange to readers who are more familiar with the classic circumstances whereby, in step four, mediation is indicated as the relationship between the initial variable and the outcome variable becomes less significant. Reassurance that perceived quality does in fact function as a mediator for quality motivated individuals can be provided by Preacher and Hayes's (2008) bootstrap method for evaluating indirect effects. Utilizing their provided SPSS macro revealed a significant effect of wait on purchase intentions through perceived quality $(Z=10.41, p<.000)$. This test, which is increasingly advocated as the standard by which mediation should be evaluated, primarily considers the relationships examined in step two and three of the Baron and Kenny procedure. Indeed there is a growing consensus that these two relationships are sufficient to demonstrate mediation (MacKinnon et al. 2002; Shrout and Bolger 2002; Zhao et al. 2010).

For convenience motivated individuals, the full model resulted in an even greater negative relationship between a required wait and purchase intentions. A bootstrap analysis, as per Preacher and Hayes (2008), of the indirect path proceeding through perceived quality was revealed to be positive and significant $(Z=8.83, p<.000)$, again indicating competitive mediation. In summary, for both groups, those motivated by quality and those motivated by convenience, a required wait increased perceived quality and subsequent purchase intentions. For those motivated by convenience, the initial negative relationship was too strong to overcome. However, for quality motivated individuals, the increased perceptions of quality resulting from the presence of a wait proved to be more powerful than the negative impact of waiting. 


\section{Study 2 Discussion}

The design of Study 2 was largely motivated by a desire to enhance the generalizability of Study 1 through examination of the proposed relationships within a variety of service settings. Thus, each participant viewed four randomly ordered service scenarios, each of which represented one of four randomly ordered experimental conditions. Within subjects designs such as this are often chosen by researchers based on their efficiency and enhanced statistical power. A potential disadvantage of within-subjects designs is that participants are exposed to all of the experimental conditions, a feature which brings with it the risk that a participant may form perceptions regarding the experimental manipulations. Undoubtedly, it is possible some participants may have inferred the goals of the study as they progressed through it. The extensive randomization procedure integrated into the design of Study 2 , however, does minimize any potential confounding influence this might have on the resulting cell means. Alternatively, even if one assumes each participant was fully aware of the experimental manipulations from the beginning of the study, the fact their responses support Hypothesis 2 also requires they intuitively understood how an interaction of motivation and required waits should affect their subsequent purchase intentions. Demonstrating how people react to stimuli is preferable to demonstrating how they think they should react to such stimuli. Either way, as this research examines how conscious evaluations of a service might affect conscious behaviors, the latter demonstration would not be without merit.

In addition to examining the proposed phenomenon across several disparate service settings, Study 2 makes a contribution to understanding the effects of waiting time on purchase intentions. Consistent with the extant literature, Study 2 finds when convenience is the primary concern, purchase intentions are decreased by the presence of a wait. However, the results also support the contention when quality is the motivating factor, the presence of a wait may increase purchase intentions regarding an unfamiliar service. The consistency of the response patterns across the student and non-student samples is encouraging. This is especially true given intuition suggests these two groups might hold very different opinions about the relative importance of quality regarding services ranging from leisure to automobile repair.

\section{Study 3}

Study 3 addresses two limitations of the previous studies, the first of which is that participants did not actually experience a product. While finding that a wait can increase purchase intentions is 
certainly interesting, demonstrating an increase in actual experienced satisfaction is perhaps more remarkable. A second limitation is that the previous studies lacked a control condition where participants had no information regarding a wait or lack thereof. The findings of Studies 1 and 2 reveal how the presence of a wait can be superior to the complete absence of a wait. A control condition, however, is needed to provide a clearer demonstration regarding the directionality of this effect. Up to this point the comparison has been between the presence of a wait and the absence of a wait; we have operated under the assumption that the presence of a wait has a positive effect on quality perceptions and purchase intentions. Additional insights can be demonstrated by examining situations in which there is no information about the presence or absence of a wait. Study 3, by its inclusion of a control condition, is designed confirm the positive relationship between perceptions of quality and purchase intentions, while at the same time extending our examination to the dependent variable of experienced satisfaction.

Study 3 Design, Stimulus and Procedure

For Study 3, 105 participants, recruited from an introductory marketing class, were randomly assigned with equal allocation to a "wait present," "wait absent," or "control" condition. Course extra credit was used as an incentive. Unlike our first two studies, Study 3 took place in a physical behavioral laboratory. This allowed the subjects to actually experience a product and report their resulting satisfaction.

Participants were informed they would taste several different products that might be offered in on-campus vending machines and were first given a sample of a sports drink to evaluate. Following the beverage sample, participants were shown a screen with a description of a retail popcorn shop and they were provided with popcorn samples. In all of the conditions, participants were told the popcorn was a new product from a Midwest popcorn retailer (see Appendix A for full text). In the "wait absent" condition a picture of this popcorn shop was included next to the description. In this picture the popcorn shop appears nearly empty with two people entering the shop. In the "wait" condition, Photoshop was used to insert a long line of people standing in front of the shop (see Fig. 3 for images). The control condition did not include an image. Next, participants consumed a serving of the popcorn and responded to measures of quality and satisfaction (see Appendix B for measures). 


\section{Study 3 Results}

A planned comparison was used to evaluate Hypothesis 3a regarding the difference between the wait present and wait absent conditions. Consistent with the previous studies, participants reported significantly higher satisfaction in the wait present condition as compared to the wait absent condition $\left(M_{\text {wait_absent }}=6.86, M_{\text {wait_present }}=7.63, t(1,102)=2.07, p=.021\right)$. Interestingly, the mean of the control condition ( $\left.M_{\text {control }}=7.21\right)$ nearly split the difference between the wait present and wait absent conditions. Thus, it would appear there was a positive effect of a wait as well as a negative effect of no wait. We should note that there was not a significant difference between the control condition (no picture) and either the wait present or wait absent condition. However, reported satisfaction in this condition, between that of the other conditions, does provide important insights with regards to the directionality of the effect(s).

For the mediation analysis examining the mechanism by which the presence of a wait might increase satisfaction, instances where participants viewed a picture featuring a long line (the wait present condition) were coded as 1 . The other two conditions, where the participants either viewed a picture featuring the absence of a line or where the participant had no information regarding the line, were both coded as 0 . An alternative method of constructing this binary variable would have been to remove the control condition from the dataset. However, this would decrease the power of the analysis, and since the purpose of the analysis was to examine the presence of a wait as compared to other circumstances the former coding scheme was adopted.

In steps one and two of the Baron and Kenny procedure, this variable was a statistically significant predictor of both satisfaction $(\beta=.179, t(1,103)=1.84, p=.034)$ and perceived quality $(\beta=.181$, $t(1,103)=1.87, p=.033)$. The relationship between perceived quality and satisfaction was also significant $(\beta=.862, t(1,103)=17.228, p<.001)$. In the final step, full mediation is demonstrated as the $0 / 1$ wait variable became insignificant $(\beta=.023, t(1,102)=0.45, p=.327)$ while the effect of perceived quality remained significant $(\beta=.857, t(1,102)=16.80, p<.000)$. The Preacher and Hayes (2008) bootstrap test for mediation was also significant $(\mathrm{Z}=1.95, \mathrm{p}=.026)$, providing further support for $\mathrm{H} 3 \mathrm{~b}$. 
Fig. 3 Study 3 -Experimental stimuli (wait absent vs. wait present)

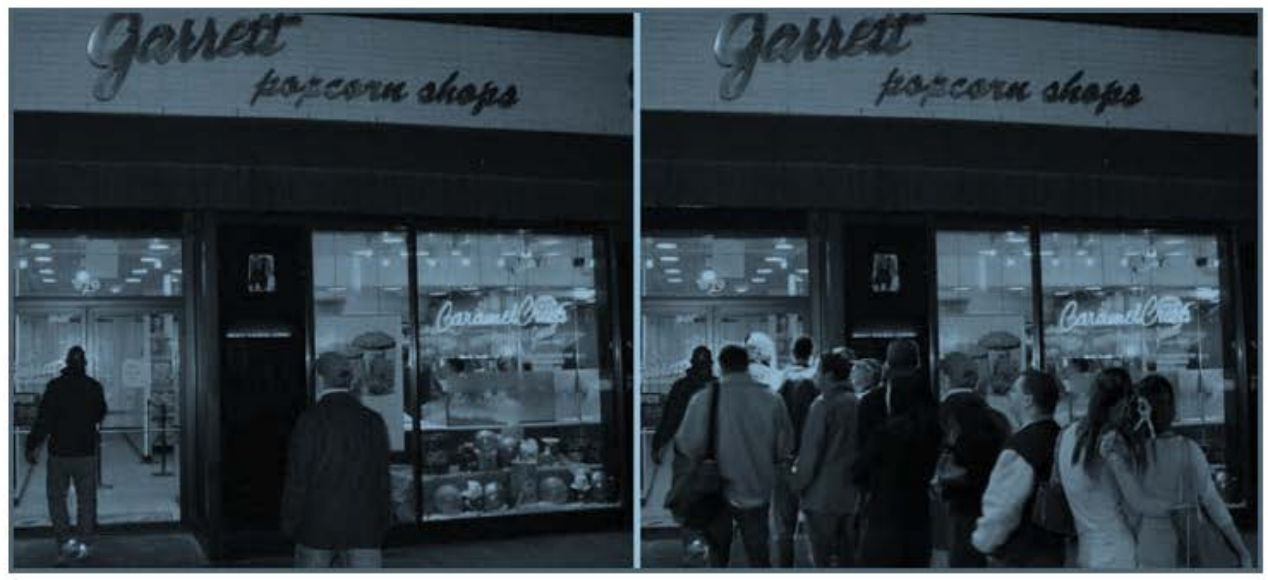

Study 3 Discussion

Perhaps the most interesting contribution of Study 3 is the demonstration that actual satisfaction can be affected by the absence or presence of a wait. While it seems counterintuitive that showing someone a picture makes popcorn taste better, this finding is consistent with the satisfaction literature which posits when goods and services are difficult to evaluate, expectations, rather than product performance, drive satisfaction judgments (Oliver and Burke 1999). It is also congruent with the wide variety of research demonstrating consumers are surprisingly bad at forming objective evaluations of anything and regularly rely on a variety of cues/signals (Lee et al. 2006; Petty et al. 1983).

Although the findings are not conclusive, the results of Study 3 suggest that, in some situations, there can be a negative effect of having no wait in addition to a positive effect of having a long wait. The implication is when marketers strive to eliminate wait times they might not only forgo an opportunity to increase consumer satisfaction, but they might be actively suppressing it (Fig. 4).

\section{Study 4}

As stated earlier, a premise of this work is that many products are inherently intangible and ambiguous. As such, signals can be influential in forming evaluations and influencing choice and purchase in such situations (Boulding and Kirmani 1993; Murray 1991). To aid in decision making, consumers often form beliefs about products prior to consumption; these beliefs affect their actual product experience (Ariely 2008; Oliver and Burke 1999). The previous studies have demonstrated the effect of a wait on an otherwise ambiguous choice; however, there are undoubtedly instances where consumers must wait for something that is not ambiguous or not difficult to evaluate on its own merits. In these situations, cues or heuristics are less influential (Chaiken and Stangor 1987). 


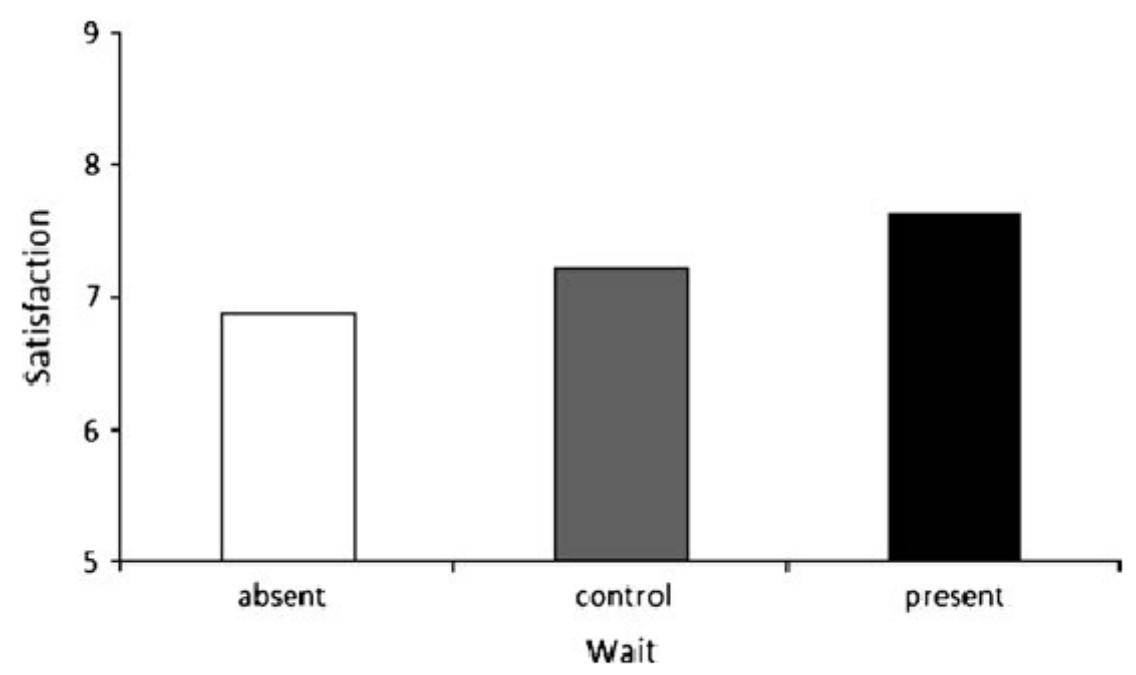

Fig. 4 Study 3 - Satisfaction

A key limitation of Studies 1-3 is that participants did not experience an actual wait; rather they were either shown a picture of a busy store or simply told how long they would have to wait for a particular product. A primary goal of Study 4 was to address this limitation. Additional motivation for Study 4 was that none of the previous studies examined the effect of waiting on perceived quality, satisfaction and purchase intentions simultaneously. Study 4 expands on Study 3 by demonstrating all these effects in the context of an actual product experience. Also, given the central role played by product ambiguity in the previous studies, an additional goal of Study 4 was to replicate the results of Study 1 while also generalizing the findings beyond "known/unknown" services.

Study 4 extends the findings of Study 3 by utilizing a design that also includes conditions where the positive effect of a wait should not be expected (i.e., where quality is not ambiguous). The presence of an interaction, whereby the effects of a wait are only positive when quality is ambiguous, provides evidence of the proposition that ambiguous product quality is a necessary pre-condition/moderator. The goals of Study 4 suggest the following hypothesis:

$\mathrm{H} 4$ : There is an interaction between ambiguity and the act of waiting such that, when quality is ambiguous, waiting increases perceived quality, satisfaction and purchase intentions. However, when quality is unambiguous, waiting has no effect on perceived quality, satisfaction, and purchase intentions.

Study 4 Design, Stimulus and Procedure

Study 4 utilized a 2 (wait: absent, present) x 2 (quality: unambiguous, ambiguous) betweensubjects experimental design. Ninety-one students from a large public university attended one of eight 
lab sessions in exchange for course extra credit. Participants were told they would be sampling two different flavors of a sports drink being developed by researchers in the Department of Food \& Nutrition Science at their university. In half of the sessions, participants were assigned to the ambiguous quality condition. In this condition participants tasted two samples of the same sports drink. The only difference between the samples was that tasteless food coloring was added to one. In other words, in this condition there were two different colors of an identical drink. In the unambiguous quality condition, clear artificial vanilla extract was added to one of the samples. Pretesting determined that this combination was distasteful. Thus, in this condition it should have been relatively easy to identify the better tasting beverage. The color which contained the vanilla was counter-balanced across lab sessions in order to avoid a potential confounds.

When participants entered the lab, there were two small $(2 \mathrm{oz})$ beverage samples at each laboratory station. Participants were instructed to taste both beverages, select their favorite flavor, and enter their choice into the online questionnaire on the computer in front of them. They were told that after they made their selection, a lab assistant would serve them a full-size version of their selected beverage that they could drink while answering more detailed questions about the product (see Appendix A).

In the wait absent condition, the researcher and a lab assistant simply distributed the full-sized drinks. In the wait present condition however, the lab assistant walked to the area of the room where the full-sized drinks were located, paused a moment, and then announced (loudly) to the researcher on the other side of the lab that she would need to go get more of one of the colors. The assistant then left the room while the researcher distributed full sized drinks to participants who had selected the other color. An announcement was made that anyone with a drink could proceed, but that those without a drink must wait. The assistant then returned approximately two minutes later and distributed the remaining drinks. The color, for which there was a wait, was also counterbalanced.

In order to execute the study's $2 \times 2$ counterbalanced design, subjects participated in one of eight lab sessions. The net result of this procedure was that in four of the eight sessions participants were presented with a very easy choice (a bad vs. good tasting beverage). In half of these unambiguous choice sessions, no one was required to wait. In the other half of the unambiguous choice sessions, nearly everyone was required to wait. In the other four lab sessions, participants sampled two different colors of the same beverage. Approximately half of the participants picked one color over the other (i.e., yellow vs. green), and approximately half of the participants waited each time. This procedure was effective in terms of generating equivalent cell sizes, although there was some minor variation 
introduced by lab session attendance. Random assignment to conditions was accomplished by randomly ordering the lab sessions.

\section{Study 4 Results}

Because Study 4 collected data on all three of the dependent variables (quality, satisfaction, and purchase intention), it provided an opportunity to examine the validity of these measures. A test of convergent and discriminant validity was conducted as per Fornell and Larcker's (1981) guidelines. A Partial Least Squares (PLS) structural model, created with SmartPLS 2.0, was used to perform a confirmatory factor analysis. The reason for using PLS as opposed to covariance based SEM is that PLS is generally viewed as more accurate when dealing with sample sizes less than 200 (Chin and Newsted 1999; Tenenhaus et al. 2005). The results (see Table 3) indicated acceptable convergent validity with all of the constructs having composite (Raykov's) reliabilities of over .90. Additionally, discriminant validity was indicated given that the average variance extracted exceeded the variance shared with the other variables. We also note, for Study 4, eleven-point scales were used. There was concern that a nine-point scale might present problems in terms of restricted range. For example, participants were asked to rate the quality of the beverage they selected (i.e., the one they preferred). Under these circumstances, it may have been odd for a participant to answer below the middle point of an item anchored by "Inferior/Superior" (see Table 3 for dependent variable correlations).

A check of the quality manipulation was accomplished using a chi-square test to evaluate the extent to which participants preferred the beverage that had not been tainted with vanilla extract. The result (chi-square $=21.967, \mathrm{p}<.001$ ) indicated a strong preference for the non-tainted beverage. However, there were eight individuals who did select the tainted beverage. There are several possibilities for this choice. One possibility is that they actually preferred this flavor; another is that, for whatever reason, they were unable to detect a difference between the two samples (e.g., a pretest participant stated a cold affected her ability to distinguish a difference). Alternatively, it is possible that participants simply clicked the wrong box on the online survey. Regardless of the reason, it was decided that excluding these individuals from further analysis would provide a clearer picture of the phenomenon under examination. 
Table 3 Study 4-Measurement evaluation

\begin{tabular}{lccc}
\hline & CR & Perceived quality & Satisfaction \\
\hline Perceived quality & $\mathbf{0 . 9 2}$ & $\mathbf{0 . 7 9}$ & Purchase intentions \\
Satisfaction & $\mathbf{0 . 9 7}$ & $0.67(0.44)$ & $\mathbf{0 . 9 1}$ \\
Purchase intentions & $\mathbf{0 . 9 5}$ & $0.73(0.53)$ & $0.72(0.52)$ \\
\hline
\end{tabular}

Average Variance Extracted presented on diagonal. Lower triangle presents latent variable correlations; squared latent variable correlations in parenthesis

MANOVA was used to evaluate $\mathrm{H} 4$ regarding the effect of the manipulations on perceived quality, satisfaction, and purchase intentions. Consistent with this hypothesis, a significant interaction was observed for all three dependant variables $(p=.003, .037$ and .004 respectively). The follow up contrasts were also consistent in supporting H4. Perceived quality, in the ambiguous quality condition, was significantly higher among those who had to wait $\left(\mathrm{M}_{\text {difference }}=1.56, \mathrm{p}=.001\right)$. When quality was unambiguous, the effect of a waiting was negative, but insignificant $\left(M_{\text {difference }}=-.49, p=.306\right)$. Similar results were found for the effect of waiting on satisfaction when quality was ambiguous $\left(M_{\text {difference }}=1.14\right.$, $\mathrm{p}=.028$ ) compared with unambiguous quality $\left(\mathrm{M}_{\text {difference }}=-.39, \mathrm{p}=.447\right)$. A similar pattern revealed itself with regards to purchase intentions. When quality was ambiguous, individuals who were required to wait reported increased purchase intentions ( $\left.M_{\text {difference }}=2.225, p=.003\right)$. When quality was unambiguous there was again an insignificant negative effect $\left(M_{\text {difference }}=-.80, p=.272\right)$.

A mediation analysis was conducted in order to evaluate perceived quality as the mechanism operating between waiting and increased satisfaction for participants in the ambiguous quality condition (H3b). The Baron and Kenny procedure demonstrated that an initially positive significant relationship between waiting and satisfaction $(\beta=.287, t(1,40)=1.90, p=.032)$ became negative and insignificant $(\beta=-.030, t(1,39)=-.234, p=.41)$ after accounting for perceived quality. Preacher and Hayes' (2008) bootstrapping test provided further evidence regarding perceived quality's mediating role $(Z=2.79$, $p=.005$ ) (Fig. 5).

\section{Study 4 Discussion}

In many ways Study 4 was a replication of Study 1 . One key difference was that participants were required to actually wait rather than simply being told that a wait was required. Additionally, the first study was somewhat limited in that it operationalized ambiguity in terms of an "unknown" service. In Study 4, all participants had firsthand knowledge of the product. The product, in some conditions, was simply difficult to objectively evaluate. This operationalization is generalizable to a wider range of situations given that intangibility is a fundamental characteristic of services. Additionally, the increasing 
parity with regards to the quality of manufactured goods suggests ambiguity will be increasingly
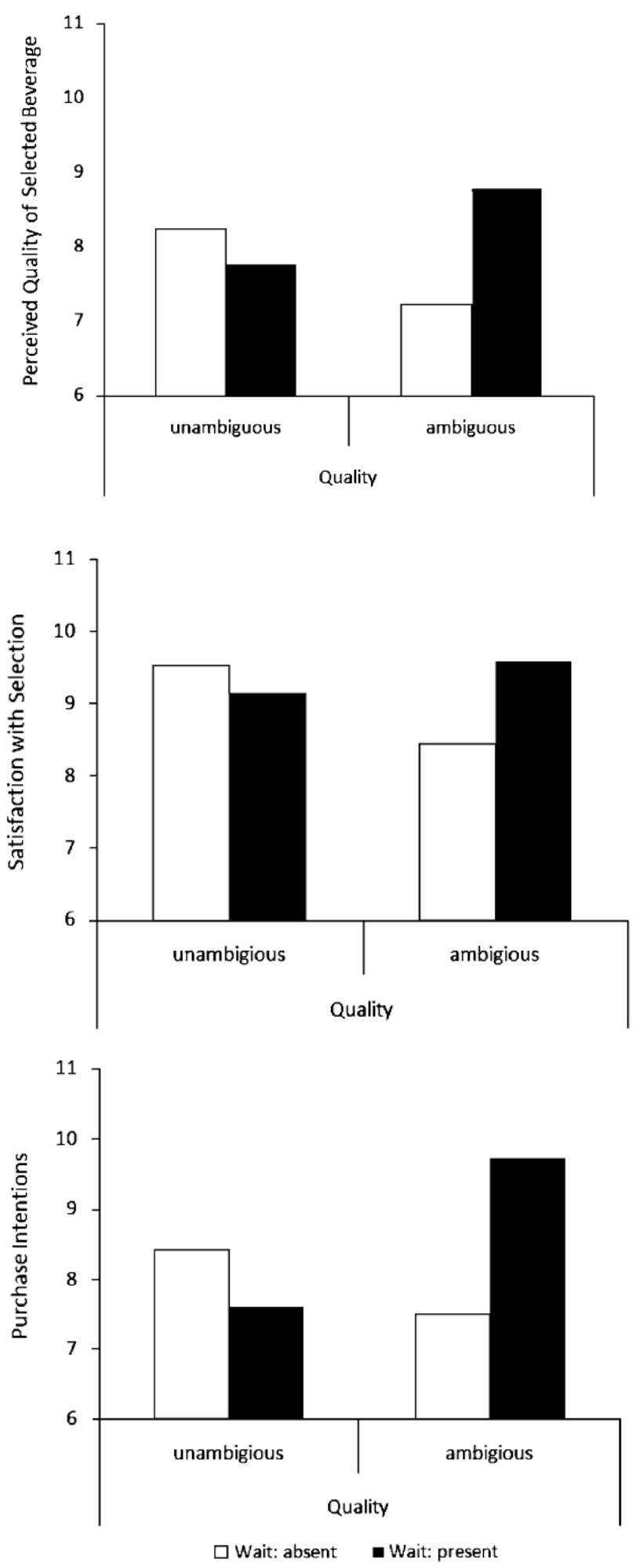

Fig. 5 Study 4 -Perceived quality, satisfaction, purchase intentions prevalent in consumption decisions involving physical goods. An additional advantage of this study, over Study 3, is the existence of conditions when a positive effect of waiting is not expected. This provides a more compelling demonstration of the effects of waiting.

While the findings of Study 4 provide support for our hypotheses, they are not inconsistent with the past findings of researchers hypothesizing the negative effects of waiting. For each dependent variable, there was a downward trend when participants were required to wait for a product that was clearly superior to the alternative. Although these effects were not significant, it is certainly possible that they might have been given a larger sample size. This is not at all troubling. The thesis of this paper is not that waits are never bad or negative. Rather the goal of this paper is to demonstrate that, under some circumstances, waits can have positive effects. These circumstances are arguably not at all rare but rather represent a large and growing percentage of consumption decisions.

\section{General Discussion}

This work appears to be the first to theorize and evaluate waiting as a positive predictor of quality assessments, purchase intentions and satisfaction, and it examines consumer waits from a different perspective than 
what has been historically presented in the marketing literature. Given the literature's consistent portrayal of waiting as a negative influence on consumer decision making, the insight lent by the research presented makes substantial contributions to both researchers and practitioners and suggests that rather than approach wait time strictly as an operational failure in need of fixing, the presence of a wait may also function as a signal of quality with the ability to increase overall evaluations. Indeed, four studies demonstrate that in terms of perceived quality, purchase intentions, and even experienced satisfaction, it may sometimes be better to make consumers wait. Regarding the circumstances under which this effect will occur, Study 1 suggests waits function as a signal of quality when consumers do not already maintain a well-defined attitude regarding the quality of a service. Study 2 demonstrates that when consumers are in search of quality (vs. convenience), the increased quality signaled by a wait is enough to overcome the negative impact of that wait. Study 3 suggests not only might a long wait have a positive effect, but eliminating wait times may have a negative effect. Lastly, Study 4 confirms the aforementioned findings by requiring an actual wait. Waiting has been labeled a "pivotal factor" in quality judgments (Hui and Tse 1996; Hui et al. 1997); the fact that this pivotal factor has only been considered as a negative element, we would argue, is to the detriment of both marketing researchers and practitioners.

Implications

For practitioners, the key implication of this research is that a more nuanced perspective of wait times should be adopted. As previously mentioned, companies spend billions of dollars annually attempting to reduce waits (Koeppen 2007). A better strategy might involve "optimizing" waits. For example, if a physical good or service is typically consumed by individuals who are both unfamiliar with the product and are in search of high quality, then eliminating the need for them to wait might actually be bad for business. More generally, if a product is difficult to evaluate (as many are), the fact that there is no wait might suggest to consumers the service is not worth waiting for. Perhaps the most dramatic implication these results provide is that appropriate waiting strategies are best defined by consumers. Specifically, the characteristics of an organization's customers are a necessary input in the designation of wait policies and procedures. Firms that experience high levels of customer turnover largely serve customers not familiar with the services available. In such cases, waiting time is likely to favorably affect the decision making of customers. Conversely, organizations largely frequented by customers intimately familiar with the services offered, either as a result of prior usage or information gathered from external sources (e.g., friends, experts, or written reviews), may be required to minimize customer waits. 
Specifically, the research results herein suggest that customers familiar with a service provider do not necessarily view waiting as a quality signal or cue. Managers, thereby, may be well advised to minimize the exposure of such customers to waits. A specific implication of these findings is that organizations need to endeavor to identify the motivation of their customers. If the motivations of a firm's customers are mixed, those seeking quality are more likely to be tolerant of waits. In fact, one might suggest that such customers expect waits when seeking quality experiences. In short, how a particular business should manage its wait times depends on both product characteristics and the characteristics of its customers.

The key implication for researchers studying waiting is that the potential positive effects of waiting in future research designs should be considered. Even if that research focuses on the negative outcomes of waiting, measuring and controlling for variables such as perceived quality and consumer motivation will result in a truer and more complete picture of the phenomenon. For example, consider the mediation analysis in Study 2: after controlling for the positive impact on purchase intentions operating via increased quality perceptions, the remaining effect of wait was found to be negative. One can see how failing to account for the positive effects of waiting could result in statistically insignificant findings, even where very strong (though counteracting) processes are present.

\section{Weaknesses and Future Research}

One weakness with the present research is that it only examines a narrow range of wait lengths. Indeed Study 4 is the only study in which participants are actually required to wait. It is very likely the case that there is a curvilinear effect of waiting on satisfaction. That is, at some point the burden of waiting will start to eliminate the increased satisfaction generated by the heightened perceptions of quality. Future research may wish to examine a wider range of wait lengths in order to develop insights regarding when this inflection point is likely to occur.

Insight into this question might be drawn from Study 2, which examines the moderating effect of consumer motivations. Seemingly, if quality is not very important, then increased satisfaction, resulting from consuming a good or service thought to be of high quality, might quickly be outweighed by the annoyance of having to wait. When quality is most important, it may take longer for the negative effects to emerge.

Another weakness of the research presented above is it does not address how a wait might interact with other signals of quality. This was purposely done in order to isolate the effect of a wait; future research to examine the interaction of wait and other quality signals could be worthwhile. In this 
study, wait was conceptualized as a cost (i.e., price). What is the impact of a wait when monetary price serves as a signal of quality? Presumably, there are situations when price is a more diagnostic signal and others when the opposite occurs. Future research may wish to explore this topic.

Additionally, consumer characteristics were not considered in our examination. For example the extant literature suggests one's need for cognition and self monitoring are individual differences likely moderating the ability of a wait to signal quality. In particular, people who pay attention to social cues, such as high self-monitors, may be more influenced by the presence of a wait caused by other people. Alternatively, individuals with a high need for cognition might be less influenced by this heuristic cue, especially if other sources of information are available (Becherer and Richard 1978; Cacioppo et al. 1984). Similarly, in situations characterized by high involvement, consumers may rely less on heuristic cues. Product category familiarity (e.g., expertise) and consumer self-confidence are two other potential moderators. Experts may pay less attention to what others are doing, while consumers with low-self confidence pay close attention to the crowd.

Additional factors that drive consumer decision making, such as economic conditions or purchase occasions, could also be investigated. Studies that employ multiple methods or longitudinal designs may provide further insights. Another possible area for future research might focus on what the consumer does while they are waiting. For example, if an individual uses the time spent waiting to elaborate on the product they are waiting for, product evaluations might become more extreme. Similar effects might be observed if an individual uses the time spent waiting to elaborate on the fact that they are waiting. Like most research projects, the studies reported identify more questions than they answer. Hopefully, this work provides a preliminary step toward a more nuanced understanding of the multidimensional phenomenon of how waiting affects consumer judgments and will serve as a catalyst for further inquiry in this area.

\section{Appendix A}

\section{Study 1}

It is Friday night and Pat is going out with a friend. They are in search of a good steak dinner. They happen upon (Outback Steakhouse/Al's Steakhouse) and decide to check it out. When they enter the building, (there is no one in the waiting area/the waiting area is full) and the hostess tells them they can be seated (right away/in approximately $45 \mathrm{~min}$ ). Imagine you are Pat and answer the following: 
Study 2

(Distracter) Pat just moved across the country to take a great job. Pat decides that one of the things that must be done, before the job actually starts, is to get a good haircut. Pat selects a salon from the phone book with an attractive ad and calls to make an appointment-the salon Pat selects says that they use all natural ingredients and the building has solar panels on roof that generate all of its electricity needs. Imagine that you are Pat and answer the following questions:

In 3 months, Pat will be leaving for a study abroad program in Asia. However, the government where the program is located requires that all visitors receive a series of vaccinations before being allowed to enter the country. The health center at Pat's school does not offer the necessary vaccinations. Pat (dislikes getting shots and wants a very good doctor to administer the vaccinations/is very busy and wants to get this out of the way as soon as possible). Pat randomly picks a doctor's office out of the phone book and calls them to ask if they offer the vaccinations. They tell Pat that they do and furthermore that appointments are available (that same day or any day of the week thereafter/in 2 months). Imagine you are Pat and answer the following:

Pat is on a weekend get-away with some close friends. It is Saturday night and they decide to go out to a club. Since it is the first time any of them have ever been to this area, they want to (spend their evening at the best club they can find/use the short time they have to sample several different clubs). They ask the person behind the front desk at their hotel for a recommendation. He gives them directions to a street where there are a number of clubs and bars. When they get there, they notice one of the clubs (doesn't have a line of people waiting to enter/has a particularly long line of people waiting to enter). Imagine you are Pat and answer the following questions:

(Distracter) Pat enters the grocery store and finds a sign posted regarding a sale on peaches. Pat heads over to check out the peaches. However, on the way Pat notices that the pears and apples look particularly tasty. Pat also notices that the price of the pears and apples is much higher than the peaches. Pat thinks to (himself/herself) that (he/she) is not really sure how much peaches usually cost. Imagine that you are Pat and answer the following questions:

The past few days, Pat's car has been making a funny noise and Pat decides that (he/she) should take it into a mechanic to get it looked at before making the 800 mile trip back home for Thanksgiving break. Pat has never had (his/her) car worked on in___ before, so (he/she) randomly picks a mechanic out of the yellow pages and calls them up to ask about setting up an appointment. The mechanic tells Pat that (there are plenty of time slots available, and that Pat should feel free to stop by any time/ they are almost completely booked up, but that that there is one time slot available early next week if Pat 
can wait). Pat tells the mechanic that (he/she) will check (his/her) schedule and call him right back. After hanging up the phone, Pat thinks to (himself/herself) that (he/she) (hopes the mechanic is a good one/hates to keep driving her car while it is making this noise and risk damaging it). Imagine that you are Pat and answer the following questions:

It's Sunday morning. Pat and his roommates are sitting around their apartment chatting over coffee. There is no food in the apartment so they decide that it would be a good idea to go out for brunch. They all agree that they should go somewhere (that is really good, because it's not often that they all have a Sunday morning with nothing else to do/that is convenient, because they all have a lot of other things to do that day). Pat mentions that (he/she) has recently seen a sign at a restaurant announcing that they serve Sunday brunch. None of them are familiar with the restaurant, but they decide to check it out. When they get there, they see that the restaurant is indeed open. Additionally, they note that the parking lot is (nearly empty and that there is no one in the waiting area/full and that there is a crowd in the waiting area). Imagine you are Pat and answer the following questions:

\section{Study 3}

The next thing you will be tasting is a new product being marketed by a small midwest popcorn retailer. It is a single serving size of their "lite butter" popcorn. This is the first time that this company has sold packaged popcorn (vs. fresh-popped). The researcher will pass around samples of this popcorn for you to try. Please eat enough to form an opinion and then wait for instructions.

\section{Study 4}

For this study, you will be sampling two different flavors of a sports drink that is being developed by researchers in the Department of Food \& Nutrition Science here at (university). In front of you is a 2 oz sample of each flavor. When instructed by the researcher, try each of the flavors and pick which one is your favorite. Please make sure you drink enough to experience the taste completely. Afterwards, you will choose your favorite and be served a 4 oz size of your chosen flavor, which you can drink while answering some more detailed questions regarding the product.

\section{Appendix B}

Dependent variable measures ${ }^{1}$

\footnotetext{
${ }^{1}$ Measured using a nine-point semantic scales for Studies 1-3, eleven-point scales for Study 4.
} 
Perceived Quality (Taylor and Bearden 2002)

Study 1: I believe my meal at this restaurant would be: $(\alpha=.947)$

Study 2: I believe this [doctor/restaurant/night club/mechanic] would be: ( $\alpha=.971)$

Study 3: I think that this popcorn is: $(\alpha=.941)$

Study 4: I think that the flavor of the [yellow/green] sports drink (the one I selected) is: $(\alpha=.866)$

$$
\begin{aligned}
& \text { Low quality/High quality } \\
& \text { Inferior/Superior } \\
& \text { Worse than most/Better than most } \\
& \text { Bad/Good (only used in studies } 1 \text { and 2) }
\end{aligned}
$$

Purchase Intentions (Oliver and Swan 1989)

Study 2: Given the situation described above, how likely is it that you would patronize this [doctor/restaurant/ night club/mechanic]? ( $\alpha=.985)$

Study 4: How likely is it that you would purchase this flavor, if it were available when you wanted to buy a sports drink? ( $\alpha=.978)$

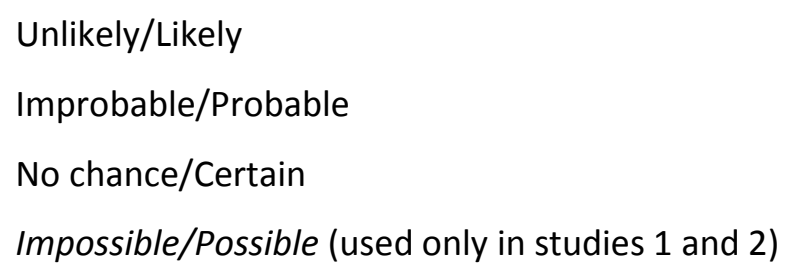

Satisfaction (Spreng et al. 1996)

Study 3: How satisfied are you with this popcorn: $(\alpha=.949)$

Study 4: How satisfied are you with your decision to choose the [yellow/green] version? ( $\alpha=.949)$ Dissatisfied/Satisfied

Displeased/Pleased

Frustrated/Contented 


\section{References}

Anderson, L., \& Holt, C. (1997). Information cascades in the laboratory. The American Economic Review, $87,847-862$.

Antonides, G., Verhoef, P. C., \& van Aalst, M. (2002). Consumer perception and evaluation of waiting time: a field experiment. Journal of Consumer Psychology, 12, 193-202.

Argo, J. J., Dahl, D. W., \& Manchanda, R. V. (2005). The influence of a mere social presence in a retail context. Journal of Consumer Research, 32, 207-212.

Ariely, D. (2008). Predictably irrational: The hidden forces that shape our decisions. New York: Harper Collins.

Baker, J., \& Cameron, M. (1996). The effects of the service environment on affect and consumer perception of waiting time: an integrative review and research propositions. Journal of the Academy of Marketing Science, 24, 338-349.

Baker, J., Parasuraman, A., Grewal, D., \& Voss, G. B. (2002). The influence of multiple store environment cues on perceived merchandise value and patronage intentions. Journal of Marketing, 66, 120141.

Banerjee, A. V. (1992). A simple model of herd behavior. Quarterly Journal of Economics, 107, 797-817.

Baron, R. M., \& Kenny, D. A. (1986). The moderator-mediator variable distinction in social psychological research: conceptual, strategic, and statistical considerations. Journal of Personality and Social Psychology, 51(6), 1173-1182.

Bearden, W. O., \& Etzel, M. J. (1982). Reference group influence on product and brand purchase decisions. Journal of Consumer Research, 9, 183-194.

Becherer, R. C., \& Richard, L. M. (1978). Self-monitoring as a moderating variable in consumer behavior. Journal of Consumer Research, 5, 159-162.

Becker, G. (1991). A note on restaurant pricing and other examples of social influences on price. Journal of Political Economy, 99, 1109-1116.

Bendapudi, N., \& Leone, R. P. (2003). Psychological implications of customer participation in coproduction. Journal of Marketing, 67, 14-28.

Berry, L. L., Seiders, K., \& Grewal, D. (2002). Understanding service convenience. Journal of Marketing, 66, 1-17.

Bitner, M. J. (1990). Evaluating service encounters: the effects of physical surroundings and employee responses. Journal of Marketing, 54, 69-82. 
Blair, M. E., \& Innis, D. E. (1996). The effects of product knowledge on the evaluation of warranted brands. Psychology and Marketing, 13, 445-456.

Bonabeau, E. (2004). The perils of the imitation age. Harvard Business Review, 82, 99-104.

Borowski, C. (2008). Actors paid to line up for iPhone launch in Poland. Retrieved August 21, 2008 from, http://www.reuters.com/article/marketsNews/idINN215519020080821?rpc=44

Boulding, W., \& Kirmani, A. (1993). A consumer-side experimental examination of signaling theory. Journal of Consumer Research, 20, 111-123.

Brady, M. K., \& Cronin, J. J., Jr. (2001). Some new thoughts on conceptualizing perceived service quality: a hierarchical approach. Journal of Marketing, 65, 34-49.

Burnkrant, R. E., \& Cousineau, A. (1975). Informational and normative social influence in buyer behavior. Journal of Consumer Research, 2, 206-215.

Cacioppo, J. T., Petty, R. E., \& Kao, C. F. (1984). The efficient assessment of need for cognition. Journal of Personality Assessment, 48(3), 306-307.

Carmon, Z., Shanthikumar, J. G., \& Carmon, T. F. (1995). A psychological perspective on service segmentation models: the significance of accounting for consumers' perceptions of waiting and service. Management Science, 41, 1806-1815.

Chaiken, S., \& Stangor, C. (1987). Attitude and attitude change. Annual Review of Psychology, 38, 575630.

Chin, W. W., \& Newsted, P. (1999). Structural equation modeling analysis with small samples using partial least squares. In R. Hoyle (Ed.), Statistical strategies for small sample research (pp. 307341). Thousand Oaks: Sage.

Cialdini, R. B. (2001). Influence: Science and practice (4th ed.). Boston: Allyn \& Bacon.

Cox, T. (2005). Scientists seek to make waiting in line more bearable. Retrieved February 2, 2009 from http://www.npr.org/templates/story/story.php?storyld=4271009

Cronin, J. J., Jr., \& Taylor, S. A. (1992). Measuring service quality: a reexamination and extension. Journal of Marketing, 56, 55-68.

Cronin, J. J., Brady, M. K., \& Hult, G. T. M. (2000). Assessing the effects of quality, value, and customer satisfaction on consumer behavioral intentions in service environments. Journal of Retailing, 76, 193-218.

Dabholkar, P. A., \& Bagozzi, R. P. (2002). An attitudinal model of technology-based self-service: moderating effects of consumer traits and situational factors. Journal of the Academy of Marketing Science, 30, 184-201. 
Dahl, D. W., Manchanda, R. V., \& Argo, J. J. (2001). Embarrassment in consumer purchase: the roles of social presence and purchase familiarity. Journal of Consumer Research, 28(3), 473-481.

Dawar, N., \& Parker, P. (1994). Marketing universals: consumers' use of brand name, price, physical appearance, and retailer reputation as signals of product quality. Journal of Marketing, 58, 8195.

Deutsch, M., \& Gerard, H. (1955). A study of normative and informational social influences upon individual judgment. Journal of Abnormal and Social Psychology, 51, 629-636.

Dodds, W. B., Monroe, K. B., \& Grewal, D. (1991). Effects of price, brand and store information on buyers' product evaluations. Journal of Marketing Research, 28, 307-319.

Dube-Rioux, L., Schmitt, B. H., \& Leclerc, F. (1989). Consumers' reactions to waiting: when delays affect the perception of service quality. Advances in Consumer Research, 16, 59-63.

Durrande-Moreau, A., \& Usunier, J. C. (1999). Time styles and the waiting experience: an exploratory study. Journal of Services Research, 2, 173-186.

Ferraro, R., Bettman, J. R., \& Chartrand, T. L. (2009). The power of strangers: the effect of incidental consumer brand encounters on brand choice. Journal of Consumer Research, 35(5), 729-741.

Fornell, C., \& Larcker, D. F. (1981). Evaluating structural equation models with unobservable variables and measurement error. Journal of Marketing Research, 18, 39-50.

Goldenberg, J., Libai, B., \& Muller, E. (2001). Talk of the network: a complex systems look at the underlying process of word-of-mouth. Marketing Letters, 12, 209-221.

Grewal, R., Cline, T. W., \& Davies, A. (2003). Early-entrant advantage, word-of-mouth communication, brand similarity, and the consumer decision-making process. Journal of Consumer Psychology, 13, 187-197.

Hui, M. K., \& Tse, D. K. (1996). What to tell consumers in waits of different lengths: an integrative model of service evaluation. Journal of Marketing, 60, 81-90.

Hui, M. K., Dubé, L., \& Chebat, J. C. (1997). The impact of music on consumers' reactions to waiting for services. Journal of Retailing, 73, 87-104.

Kirmani, A., \& Rao, A. R. (2000). No pain, no gain: a critical review of the literature on signaling unobservable product quality. Journal of Marketing, 64, 66-79.

Koeppen, S. (2007). Companies heeding gripes about long lines. Retrieved March 1, 2008 from http://www.cbsnews.com/stories/2007/04/09/earlyshow/contributors/susankoeppen/main266 3189.shtml 
Kumar, P., Kalwani, M. U., \& Dada, M. (1997). The impact of waiting time guarantees on customers' waiting experiences. Marketing Science, 16, 295-314.

Latane, B. (1981). The psychology of social impact. The American Psychologist, 36, 343-356.

Leclerc, F., Schmitt, B. H., \& Dubé, L. (1995). Waiting time and decision making: is time like money? Journal of Consumer Research, 22, 110-119.

Lee, L., Frederick, S., \& Ariely, D. (2006). Try it, you'll like it: the influence of expectation, consumption, and revelation on preferences for beer. Psychological Science, 17, 1054-1058.

MacKinnon, D. P., Lockwood, C. M., Hoffman, J. M., West, S. G., \& Sheets, V. (2002). A comparison of methods to test mediation and other intervening variable effects. Psychological Methods, 7, 83104.

Morganosky, M. A. (1986). Cost-versus convenience-oriented consumers: demographic, lifestyle, and value perspectives. Psychology and Marketing, 3, 35-46.

Murray, K. B. (1991). A test of services marketing theory: consumer information acquisition activities. Journal of Marketing, 55, 10-25.

Nock, M. K. (2008). Actions speak louder than words: an elaborated theoretical model of the social function of self-injury and other harmful behaviors. Applied and Preventive Psychology, 12, 159168.

Oliver, R. L. (1980). A cognitive model of the antecedents and consequences of satisfaction decisions. Journal of Marketing Research, 17, 460-469.

Oliver, R. L., \& Burke, R. R. (1999). Expectation processes in satisfaction formation: a field study. Journal of Service Research, 1, 196-214.

Oliver, R. L., \& Swan, J. E. (1989). Consumer perceptions of interpersonal equity and satisfaction in transactions: a field survey approach. Journal of Marketing, 53, 21-35.

Petty, R. E., Cacioppo, J. T., \& Schumann, D. (1983). Central and peripheral routes to advertising effectiveness: the moderating role of involvement. Journal of Consumer Research, 10, 135-146.

Preacher, K. J., \& Hayes, A. F. (2008). Asymptotic and resampling strategies for assessing and comparing indirect effects in multiple mediator models. Behavior Research Methods, 40(3), 879-891.

Rao, A. R., \& Monroe, K. B. (1989). The effect of price, brand name, and store name on buyers' perceptions of product quality: an integrative review. Journal of Marketing Research, 26, 351357. August.

Senecal, S., \& Nantel, J. (2004). The influence of online product recommendations on consumers' online choices. Journal of Retailing, 80, 159-169. 
Shrout, P. E., \& Bolger, N. (2002). Mediation in experimental and nonexperimental studies: new procedures and recommendations. Psychological Methods, 7, 422-445.

Sirohi, N., McLaughlin, E. W., \& Wittink, D. R. (1998). A model of consumer perceptions and store loyalty intentions for a supermarket retailer. Journal of Retailing, 74(2), 223-45.

Spreng, R. A., MacKenzie, S. B., \& Olshavsky, R. W. (1996). A reexamination of the determinants of consumer satisfaction. Journal of Marketing, 60, 15-32.

Taylor, S. (1994). Waiting for service: the relationship between delays and evaluations of service. Journal of Marketing, 58, 56-69.

Taylor, S. (1995). The effects of filled waiting time and service provider control over the delay on evaluations of service. Journal of the Academy of Marketing Science, 23, 38-48.

Taylor, V. A., \& Bearden, W. O. (2002). The effects of price on brand extensions evaluation: the moderating role of extension similarity. Journal of the Academy of Marketing Science, 30, 13140.

Tenenhaus, M., Vinzi, V. E., Chatelin, Y., \& Lauro, C. (2005). PLS path modeling. Computational Statistics and Data Analysis, 48, 159-205.

Zeithaml, V. A. (1988). Consumer perceptions of price, quality, and value: a means-end model and synthesis of evidence. Journal of Marketing, 52, 2-22.

Zeithaml, V. A., Berry, L. L., \& Parasuraman, A. (1996). The behavioral consequences of service quality. Journal of Marketing, 60, 31-46.

Zhao, X., Lynch, J. G., \& Chen, Q. (2010). Reconsidering Baron and Kenny: myths and truths about mediation analysis. Journal of Consumer Research, 37, 197-206. 